\title{
Acute exposure to lead increases myocardial contractility independent of hypertension development
}

\author{
M. Fioresi ${ }^{1,2}$, L.B. Furieri ${ }^{1}$, M.R. Simões ${ }^{1}$, R.F. Ribeiro Junior ${ }^{1}$, E.F. Meira ${ }^{1}$, A.A. Fernandes ${ }^{1}$, \\ I. Stefanon ${ }^{1}$ and D.V. Vassallo ${ }^{1,3}$ \\ ${ }^{1}$ Programa de Pós-Graduação em Ciências Fisiológicas, Centro de Ciências da Saúde, \\ Universidade Federal do Espírito Santo, Vitória, ES, Brasil \\ ${ }^{2}$ Departamento de Enfermagem, Centro de Ciências da Saúde, Universidade Federal do Espírito Santo, \\ Vitória, ES, Brasil \\ ${ }^{3}$ Centro de Ciências da Saúde de Vitória, Escola Superior de Ciências da Santa Casa de Misericórdia de Vitória, \\ Vitória, ES, Brasil
}

\begin{abstract}
We studied the effects of the acute administration of small doses of lead over time on hemodynamic parameters in anesthetized rats to determine if myocardial contractility changes are dependent or not on the development of hypertension. Male Wistar rats received $320 \mu \mathrm{g} / \mathrm{kg}$ lead acetate iv once, and their hemodynamic parameters were measured for $2 \mathrm{~h}$. Cardiac contractility was evaluated in vitro using left ventricular papillary muscles as were $\mathrm{Na}^{+}, \mathrm{K}^{+}$-ATPase and myosin Ca ${ }^{2+}$-ATPase activities. Lead increased left- (control: $112 \pm 3.7$ vs lead: $129 \pm 3.2 \mathrm{mmHg}$ ) and right-ventricular systolic pressures (control: $28 \pm 1.2$ vs lead: $34 \pm 1.2 \mathrm{mmHg}$ ) significantly without modifying heart rate. Papillary muscles were exposed to $8 \mu \mathrm{M}$ lead acetate and evaluated $60 \mathrm{~min}$ later. Isometric contractions increased (control: $0.546 \pm 0.07 \mathrm{vs} \mathrm{lead:} 0.608 \pm 0.06 \mathrm{~g} / \mathrm{mg}$ ) and time to peak tension decreased (control: $268 \pm 13$ vs lead: $227 \pm 5.58 \mathrm{~ms}$ ), but relaxation time was unchanged. Post-pause potentiation was similar between groups ( $n=6$ per group), suggesting no change in sarcoplasmic reticulum activity, evaluated indirectly by this protocol. After 1-h exposure to lead acetate, the papillary muscles became hyperactive in response to a $\beta$-adrenergic agonist $(10 \mu \mathrm{M}$ isoproterenol). In addition, post-rest contractions decreased, suggesting a reduction in sarcolemmal calcium influx. The heart samples treated with $8 \mu \mathrm{M}$ lead acetate presented increased $\mathrm{Na}^{+}, \mathrm{K}^{+}-\mathrm{ATPase}$ (approximately 140\%, P $<0.05$ for control vs lead) and myosin ATPase (approximately 30\%, P $<0.05$ for control vs lead) activity. Our results indicated that acute exposure to low lead concentrations produces direct positive inotropic and lusitropic effects on myocardial contractility and increases the right and left ventricular systolic pressure, thus potentially contributing to the early development of hypertension.
\end{abstract}

Key words: Lead; Myocardial contractility; Ventricular pressure

\section{Introduction}

Lead is a toxic metal and an environmental pollutant related to the development of hypertension, in addition to having harmful effects on the neural, renal and cardiovascular systems, among others (1-4). Its effects on human health depend on blood levels and the duration of the exposure (5). Navas-Acien et al. (6) reviewed the link between lead exposure and cardiovascular events in various population studies, highlighting the elevation of arterial pressure (7-9). Lead-induced hypertension involves an increase of sympathetic nerve activity and a reduction of baroreflex sensitivity (10-12).
However, the cardiovascular effects of lead are not limited to increases in blood pressure. While lead-induced hypertension has been well described, only a few reports have described the direct effects of lead on cardiac muscle (13). Carmignani et al. (14) reported a positive inotropic effect and the increased activity of angiotensinconverting enzyme in rats exposed to $60 \mathrm{ppm}$, as drinking water, of lead acetate for 10 months. Moreover, Prentice and Kopp (15), also using perfused hearts, demonstrated that $30 \mu \mathrm{M}$ lead attenuated the positive inotropic response of increasing calcium concentrations. In agree-

Correspondence: M. Fioresi, Departamento de Ciências Fisiológicas, CBM/UFES, Av. Marechal Campos, 1468, $29040-095$ Vitória, ES, Brasil. Fax: +55-27-3335-7330. E-mail: mirianfioresi@hotmail.com 
ment with those findings, Bernal et al. (16), using 1 to $30 \mu \mathrm{M}$ lead, also reported calcium channel blocker action in rat myocytes and Xenopus laevis oocytes. In papillary muscles, acute $100 \mu \mathrm{M}$ lead added to the bath had a negative inotropic effect (17), suggesting that lead affects heart function. However, it is necessary to emphasize that low lead concentrations (24.2 $\pm 1.8 \mu \mathrm{g} / \mathrm{dL})$ cause positive inotropism (14), while negative inotropism has been associated with higher lead concentrations (100 $\mu \mathrm{M})$ (17).

The cardiac effects resulting from acute administration of low concentrations of lead acetate are still poorly understood. There is a need to know whether even a short exposure to low lead concentrations can cause significant deleterious effects on important components of cardiovascular function. If deleterious effects occur, they could be related to cardiovascular pathophysiology and should be potentially noteworthy in the context of epidemiological impact.

In the present study, we investigated the acute effects of low concentrations of lead over time on hemodynamic parameters in anesthetized rats to determine if myocardial contractility changes are dependent on hypertension development. To this end, we also measured in vitro the isometric twitch and tetanic contractions of the left ventricular papillary muscles and myosin ATPase and $\mathrm{Na}^{+}, \mathrm{K}^{+}$-ATPase activities.

\section{Material and Methods}

\section{Animals and ethics statement}

Studies were performed using male Wistar rats (280$350 \mathrm{~g}$ ). Rat chow and water were provided ad libitum. All experiments were conducted in compliance with the guidelines for Biomedical Research as stated by the Brazilian Societies of Experimental Biology. The experimental procedures were approved by the Ethics Committee in Animal Experimentation of the Escola Superior de Ciências da Santa Casa de Misericórdia de Vitória (CEUA-EMESCAM; protocols \#003/2007 and $\# 007 / 2007)$ and are in agreement with the Ethical Principles in Animal Experimentation of the Sociedade Brasileira de Ciência em Animais de Laboratório (SBCAL).

\section{Hemodynamics}

Rats were anesthetized with urethane $(1.2 \mathrm{mg} / \mathrm{kg}$, ip), and the femoral vein, carotid artery, and jugular vein were cannulated. The carotid artery and jugular vein cannulas were advanced into the left and right ventricular chambers, respectively, and connected to transducers (TSD 104A, Biopac Systems, Inc., USA) for pressure measurements and recordings. The following parameters were analyzed: left and right ventricular systolic pressures (LVSP and RVSP), heart rate (HR), and the positive (+) and negative (-) time derivatives of the left and right ventricular pressures $(\mathrm{dP} / \mathrm{dt})$.

The following protocols were applied to anesthetized rats. The acute effects were achieved using a bolus dose of intravenously injected lead acetate $(320 \mu \mathrm{g} / \mathrm{kg})$. This amount was selected to produce a blood concentration near $160 \mu \mathrm{g} / \mathrm{dL}$ (approximately $8 \mu \mathrm{M}$ ) considering that the lead was dissolved in a volume equivalent to $20 \%$ body weight that corresponds to the extracellular fluid volume, approximately $20 \mathrm{~mL} / 100 \mathrm{~g}$ in rats.

All animals $(n=9)$ were monitored for $120 \mathrm{~min}$, and the LVSP, RVSP, HR, and $\mathrm{dP} / \mathrm{dt}+$ and $\mathrm{dP} / \mathrm{dt}$ - time derivatives of left and right ventricular pressures were recorded before lead administration (control condition, time $0, \mathrm{Ct}$ ) and at 30, 60, 90, and 120 min following lead administration. Similar protocols were repeated to establish time controls in animals that only received saline injections $(n=4)$.

\section{Isometric contractility study using papillary muscles}

Rats were anesthetized with $10 \%$ chloral hydrate (65 mg/kg, ip), the thorax was opened, and the heart was rapidly removed. The hearts were perfused through the aortic stump with modified Tyrode's solution (120 mM $\mathrm{NaCl}, 5.4 \mathrm{mM} \mathrm{KCl}, 1.2 \mathrm{mM} \mathrm{MgCl}$, $1.25 \mathrm{mM} \mathrm{CaCl}_{2}$, $20 \mathrm{mM}$ HEPES buffer, and $11 \mathrm{mM}$ glucose, $\mathrm{pH} 7.4$ ) allowing the proper selection and dissection of the left ventricular papillary muscles. The muscles were mounted in a specific apparatus (Schuler-Organbad; Hugo Sachs Elektronik, Germany) to evaluate the isometric force that was normalized to the respective papillary weight (papillary weight $=5.85 \pm 2.12 \mathrm{mg}, \mathrm{n}=33$ ). The preparations were bathed in a $20-\mathrm{mL}$ water-jack bath that was maintained at $26 \pm 0.5^{\circ} \mathrm{C}$ to avoid hypoxia of the muscle core and was gassed with $100 \% \mathrm{O}_{2}$. The preparations were attached to an isometric transducer (TSD125, Biopac Systems, Inc.). Field stimulation was provided by isolated rectangular pulses (10 to $15 \mathrm{~V}$ in $12-\mathrm{ms}$ duration) applied through a pair of platinum electrodes placed along the whole extension of the muscle. The standard rate of stimulation was $0.5 \mathrm{~Hz}$. The recordings were started after 45 to $60 \mathrm{~min}$ to let the beating preparation adapt to the new environmental conditions. The force developed during the contractions was measured in $\mathrm{g} / \mathrm{mg}$ (developed force divided by muscle weight in $\mathrm{mg}$ ). Correction by papillary weight was used to normalize the data from different preparations.

To evaluate the acute effects of lead on papillary muscle contractility, we used $8 \mu \mathrm{M}$ lead acetate to reproduce a condition similar to the one obtained in vivo. Lead was added to the bath after stabilization of the preparation and contractility parameters were determined at 0 (control condition), 15, 30, 45, and 60 min after lead administration. Tests were performed at optimum length for contraction (Lmax) before and after exposure to lead acetate. The following parameters were determined: peak isometric force, time to peak tension (TPT), relaxation 
time, and the $\mathrm{dP} / \mathrm{dt}+$ and $\mathrm{dP} / \mathrm{dt}$ - time derivatives of left ventricular force development.

The effects of $8 \mu \mathrm{M}$ lead acetate were also investigated in the following protocols: post-pause potentiation (PPP), post-rest contraction (PRC) and $\beta$-adrenergic stimulation with $10 \mu \mathrm{M}$ isoproterenol. PPP, taken as an indicator of sarcoplasmic reticulum $\mathrm{Ca}^{2+}$ release (18), was measured after a pause interval of 15,30 , and $60 \mathrm{~s}$, and these results are presented as relative potentiation (the amplitude of post-rest contractions divided by steadystate contractions) to compare potentiation after steadystate contractions of different amplitudes. PRCs were obtained after $10 \mathrm{~min}$ without stimulation and in the calcium-free solution containing $5 \mathrm{mM}$ caffeine. To achieve PRC, seconds before the electric stimulation, the calcium-free solution was replaced with modified Tyrode's solution (with $1.25 \mathrm{mM}$ calcium). The first contraction after rest was taken as an index of sarcolemmal calcium influx (18). Taking into account that the rat myocardium saturates its positive inotropic response at extracellular $\mathrm{Ca}^{2+}$ concentrations lower than those for other species (17), the protocols using isoproterenol were performed with reduced extracellular $\mathrm{Ca}^{2+}$ concentrations $(0.62 \mathrm{mM})$. In the last protocol, tetanic tension was elicited before (control condition - time 0 ) and at 15, 30, 45, 60, and $90 \mathrm{~min}$ after lead administration by high frequency stimulation $(10 \mathrm{~Hz}$ for $15 \mathrm{~s}$ ). Tetanus was achieved after $5 \mathrm{mM}$ caffeine pretreatment for $30 \mathrm{~min}$, and a time interval of 15 min was used between tetanic stimulations.

Time control protocols were performed in preparations $(n=4)$ without exposure to lead.

\section{Cardiac myosin ATPase activity}

Another group of animals ( $n=6$ per group) was sacrificed, and their hearts were rapidly frozen in liquid nitrogen and kept at $-80^{\circ} \mathrm{C}$ until analysis

Myosin was prepared from minced and homogenized left ventricles extracted briefly with $\mathrm{KCl}$-phosphate buffer (0.3 M KCl and $0.2 \mathrm{M}$ phosphate buffer, pH 6.5 (19). After precipitation of myosin with a 15-fold dilution with water, the muscle residue was separated by filtration using cheesecloth. This procedure precipitates cell fragments, including the membranes. The filtrate containing myosin was centrifuged at $10,000 \mathrm{~g}$ for $40 \mathrm{~min}$. The precipitate was re-dissolved in phosphate buffer and $0.6 \mathrm{M} \mathrm{KCl}$ for elution of myosin under high ionic strength, and $1 \mathrm{~mL}$ water was added for each $\mathrm{g}$ of tissue to produce a new precipitate. The material was again centrifuged at $10,000 \mathrm{~g}$ for $40 \mathrm{~min}$, and the muscle residue separated by filtration. The material was re-dissolved again in $14 \mathrm{~mL}$ water per $\mathrm{g}$ tissue, centrifuged and filtered as before. The precipitate was dissolved in $50 \mathrm{mM} \mathrm{N}$-(2-hydroxyethylpiperazine- $\mathrm{N}^{\prime}$-[2-ethanesulfonic acid]) sodium salt (HEPES, $\mathrm{pH} 7.0$ ) and $0.6 \mathrm{M} \mathrm{KCl}$ plus $50 \%$ glycerol (v/v) and stocked at $-20^{\circ} \mathrm{C}$. Stocked myosin had to be diluted in water (1:12) and centrifuged at 10,000 $\mathrm{g}$ for $40 \mathrm{~min}$. The precipitate was re-suspended in $50 \mathrm{mM}$ HEPES, $\mathrm{pH}$ 7.0, and $0.6 \mathrm{M} \mathrm{KCl}$, and centrifuged at $600 \mathrm{~g}$ for $5 \mathrm{~min}$. The supernatant was used for enzyme assays.

Myosin ATPase activity was assayed as described in previous reports $(19,20)$ by measuring inorganic phosphate $(\mathrm{Pi})$ liberation from $1 \mathrm{mM} \mathrm{ATP}$ in the presence of $50 \mathrm{mM}$ HEPES, $\mathrm{pH} 7.0,0.6 \mathrm{M} \mathrm{KCl}, 5 \mathrm{mM} \mathrm{CaCl}_{2}$, or $10 \mathrm{mM}$ ethylene glycol-bis ( $\beta$-amino ethyl ether$\mathrm{N}, \mathrm{N}, \mathrm{N}^{\prime}, \mathrm{N}^{\prime}$-tetra acetic acid (EGTA) in a final volume of $200 \mu \mathrm{L}$. ATP was added to the reaction mixture and preincubated for $5 \mathrm{~min}$ at $30^{\circ} \mathrm{C}$. The reaction was initiated by adding the enzyme fraction (3-5 $\mu \mathrm{g}$ protein) to the reaction mixture. The incubation time (10 $\mathrm{min}$ ) and protein concentration were chosen to be in the range of reaction linearity. The samples were assayed in duplicate or triplicate and corrected for non-enzymatic hydrolysis by using controls assayed under the same conditions, except that the protein sample was added after the interruption of the reaction by using $200 \mu \mathrm{L} 10 \%$ trichloroacetic acid. The reaction was initiated by the addition of the protein sample to avoid the inactivation at $30^{\circ} \mathrm{C}$ caused by a lack of substrate. The enzyme activity was calculated as the difference between the activity observed in the presence of $\mathrm{Ca}^{2+}$ and that in the presence of $10 \mathrm{mM}$ EGTA. Pi was determined by the method of Chan et al. (18). The specific activity was reported as $\mathrm{nmol} P$ i released per min per $\mathrm{mg}$ protein. Protein levels were measured by the method of Bradford (21) using bovine serum albumin as a standard. To determine whether lead acetate can affect myosin ATPase activity, the aforementioned protocol was conducted in the absence and presence of $8 \mu \mathrm{M}$ lead acetate $(n=6)$.

\section{$\mathrm{Na}^{+}, \mathrm{K}^{+}$-ATPase activity}

To determine whether lead acetate $(8 \mu \mathrm{M})$ can affect $\mathrm{Na}^{+}, \mathrm{K}^{+}$-ATPase activity, enzymatic material was extracted as described by Stefanon et al. (22). Ventricular tissue ( $n=6$ per group) was homogenized in a solution containing $20 \mathrm{mM}$ Tris- $\mathrm{HCl}$ and $1 \mathrm{mM}$ EDTA, $\mathrm{pH}$ 7.5. The homogenized tissue was centrifuged at $10,000 \mathrm{~g}$ for $20 \mathrm{~min}$, and the precipitate was discarded. The same volume of $20 \mathrm{mM}$ Tris- $\mathrm{HCl}$ and $1 \mathrm{mM}$ EDTA, $\mathrm{pH} 7.5$, was added to the supernatant and centrifuged at $10,500 \mathrm{~g}$ again for $1 \mathrm{~h}$. The precipitate was resuspended in $20 \mathrm{mM}$ Tris- $\mathrm{HCl}$ and $1 \mathrm{mM}$ EDTA, $\mathrm{pH} 7.5$, in a final volume of $400 \mu \mathrm{L}$.

$\mathrm{Na}^{+}, \mathrm{K}^{+}$-ATPase activity was assayed by measuring $\mathrm{Pi}$ liberation from $3 \mathrm{mM}$ ATP in the presence of $125 \mathrm{mM}$ $\mathrm{NaCl}, 3 \mathrm{mM} \mathrm{MgCl}, 20 \mathrm{mM} \mathrm{KCl}$ and $50 \mathrm{mM}$ Tris- $\mathrm{HCl}$, $\mathrm{pH}$ 7.5. The enzyme was pre-incubated for $5 \mathrm{~min}$ at $37^{\circ} \mathrm{C}$, and the reaction was initiated by adding ATP. Incubation time and protein concentration were chosen to ensure reaction linearity. The reaction was stopped by the addition of $200 \mu \mathrm{L} 10 \%$ trichloroacetic acid. Controls were prepared by the addition of the enzyme preparation after 
the addition of trichloroacetic acid and were used to correct for the non-enzymatic hydrolysis of the substrate. All samples were tested in duplicate. Specific activity is reported as $\mathrm{nmol} \mathrm{Pi}$ released per min per mg of protein, unless otherwise stated. The specific activity of the enzyme was determined in the presence and absence of $5 \mathrm{mM}$ ouabain.

\section{Drugs used}

The following drugs were used: heparin (Roche Q.F.S.A., Brazil), anhydrous caffeine (B. Herzog, Brazil), chloral hydrate (Reagen, Brazil), urethane, bovine serum albumin, lead acetate, HEPES and (-) isoproterenol hydrochloride (Sigma, USA). All other reagents used were of analytical grade and were obtained from Sigma, E. Merck (Germany), or Reagen.

\section{Data analysis and statistics}

Data are reported as means \pm SE. Comparisons between the means were made using repeated measures ANOVA or the Student $t$-test. A significant ANOVA was followed by the Tukey test. The level of significance was set at $\mathrm{P}<0.05$. Figures were plotted using the GraphPad Prism $^{\mathrm{TM}}$ version 5.0 software (GraphPad Software, USA) and data were analyzed statistically using the GB-STAT software (version 4.0, Dynamic Microsystem Inc., USA).

\section{Results}

Table 1 shows the effects of lead administered iv on the time course changes of hemodynamic parameters. Sixty minutes after lead administration, the LVSP and RVSP and corresponding positive $(\mathrm{dP} / \mathrm{dt}+)$ and negative (dP/dt-) derivatives increased, but HR remained unchanged.

Animals that received only vehicle injections were considered as a time control. In this group, left and right ventricular pressures, their derivatives and HR were unchanged (data not shown).

Figure 1 displays the effects of exposure to $8 \mu \mathrm{M}$ lead acetate over 60 min on force, TPT and the corresponding positive and negative time derivatives. The force and both time derivatives increased after lead exposure. TTP was reduced, but relaxation time did not change (data not shown). To investigate the putative role of the sarcoplasmic reticulum and sarcolemmal calcium influx, two protocols examining PPP and PRC, respectively, were performed. PPP was unchanged, suggesting that the sarcoplasmic reticulum was not involved (at least at this concentration; data not shown). However, PRC was reduced, aproximately $50 \%$, suggesting a lead effect blocking the sarcolemmal calcium influx. This finding was reinforced by the reduction of the peak tetanic tension (Figure 2), whereas the plateau tension did not change (control: $0.215 \pm 0.02$ vs lead: $0.190 \pm 0.03 \mathrm{~g} / \mathrm{mg} ; \mathrm{P}>$ 0.05).

As a time control protocol, papillary muscles were investigated without lead exposure. Force parameters and time derivatives did not change (data not shown).

Knowing that chronic lead exposure increases sympathetic activity, we used a single dose of isoproterenol, a $\beta$-adrenoceptor agonist, to investigate this issue (10-12). Isoproterenol increased the percentage of force development following lead administration in vitro (control: 39.14 \pm 6.15 vs lead: $64.43 \pm 8.71 \%$; $P<0.05)$.

In agreement with previous reports (16), our findings indicated that lead reduced PRC, suggesting that the metal acts as a calcium channel blocker. These results raise the question of how the pressure and force were increased. To clarify this issue, we investigated the effects of lead on myosin ATPase activity. Figure 3 presents the increase in myosin ATPase activity after acute lead acetate administration. However, TPT was reduced (Figure 1), suggesting that calcium could be released faster into the myoplasm. This possibility was ruled out because PPP was not affected (data not shown). This finding led us to investigate the possibility of increased contractile synchronization. This mechanism had already been reported to be linked to increased $\mathrm{Na}^{+}, \mathrm{K}^{+}$-ATPase activity producing hyperpolarization (23). As previously

Table 1. Effects of lead on the time course changes of hemodynamic parameters of anesthetized rats.

\begin{tabular}{|c|c|c|c|c|c|}
\hline & $0 \mathrm{~min}$ & $30 \mathrm{~min}$ & $60 \min$ & $90 \mathrm{~min}$ & $120 \min$ \\
\hline LVSP (mmHg) & $112 \pm 3.7$ & $123 \pm 4.7$ & $127 \pm 4.4^{*}$ & $129 \pm 4.3^{*}$ & $129 \pm 3.2^{*}$ \\
\hline $\mathrm{dP} / \mathrm{dt}+\mathrm{LV}(\mathrm{mmHg} / \mathrm{s})$ & $5731 \pm 753$ & $6761 \pm 891^{*}$ & $6892 \pm 786^{*}$ & $7269 \pm 881^{*}$ & $7518 \pm 869^{*}$ \\
\hline $\mathrm{dP} / \mathrm{dt}-\mathrm{LV}(\mathrm{mmHg} / \mathrm{s})$ & $-5330 \pm 504$ & $-5868 \pm 442$ & $-5937 \pm 436$ & $-6249 \pm 438^{*}$ & $-6507 \pm 443^{*}$ \\
\hline RVSP (mmHg) & $28 \pm 1.2$ & $30.5 \pm 1.6$ & $33 \pm 1.1^{*}$ & $34 \pm 1.0^{*}$ & $34 \pm 1.2^{*}$ \\
\hline $\mathrm{dP} / \mathrm{dt}+\mathrm{RV}(\mathrm{mmHg} / \mathrm{s})$ & $1721 \pm 179$ & $1888 \pm 203$ & $2024 \pm 182$ & $2140 \pm 193^{*}$ & $2224 \pm 177^{*}$ \\
\hline $\mathrm{dP} / \mathrm{dt}-\mathrm{RV}(\mathrm{mmHg} / \mathrm{s})$ & $-1662 \pm 108$ & $-1762 \pm 153$ & $-1979 \pm 135^{*}$ & $-1873 \pm 87$ & $-1959 \pm 98^{*}$ \\
\hline $\mathrm{HR}(\mathrm{bpm})$ & $312 \pm 22$ & $330 \pm 23$ & $331 \pm 17$ & $334 \pm 16$ & $334 \pm 17$ \\
\hline
\end{tabular}

Data are reported as means \pm SE for 9 animals. Changes in left ventricular (LV) and right ventricular (RV) pressures of anesthetized rats are shown. Zero time is the control condition. RV and LV parameters were obtained before and during 120 min of exposure to lead acetate $(320 \mu \mathrm{g} / \mathrm{kg}, i \mathrm{~V}) . \mathrm{LVSP}=\mathrm{LV}$ systolic pressure; RVSP = RV systolic pressure; $\mathrm{dP} / \mathrm{dt}=$ positive $(+)$ and negative $(-)$ rate of rise of left ventricular pressure; $\mathrm{HR}=$ heart rate. ${ }^{*} \mathrm{P}<0.05$ for lead $v s$ control (one-way repeated measures ANOVA followed by the Tukey test). 
A

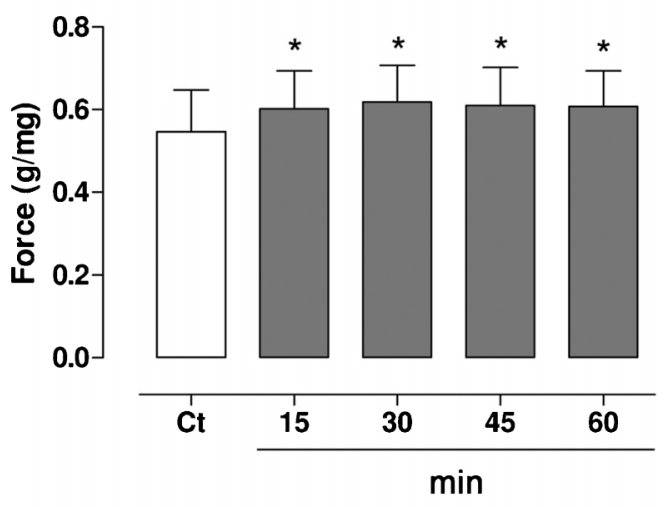

C

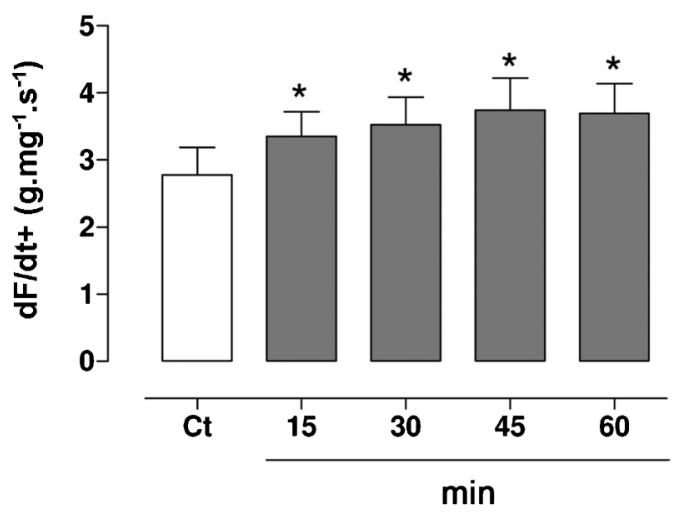

B

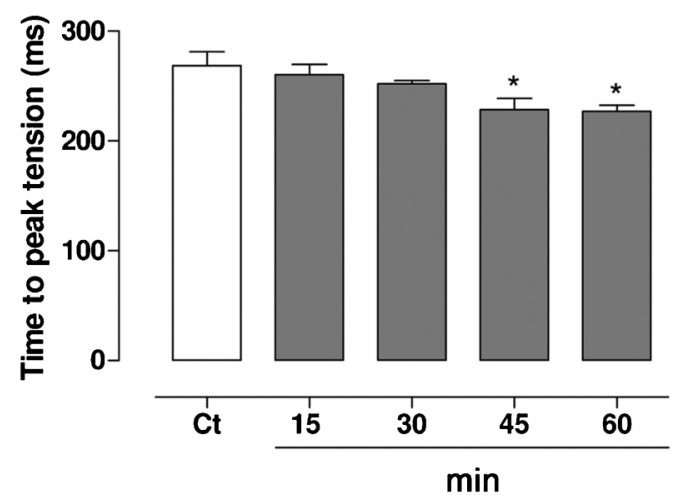

D

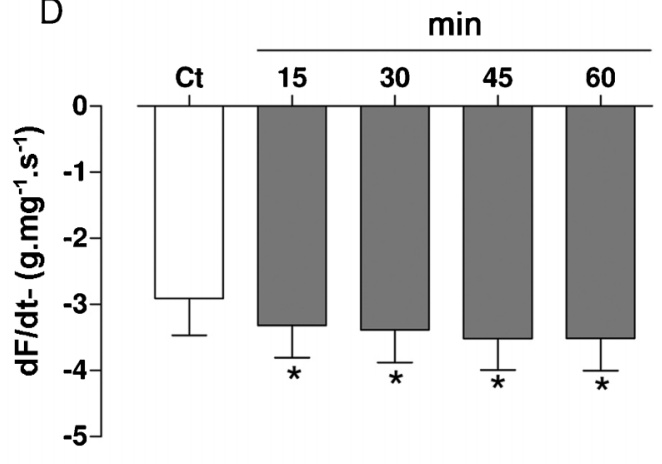

Figure 1. Effects of $8 \mu \mathrm{M}$ lead acetate on the time course changes of isometric force $(A)$, time to peak tension $(B), \mathrm{dF} / \mathrm{dt}+(C)$ and $\mathrm{dF} / \mathrm{dt}-$ $(D)$ of rat left ventricular papillary muscles. Results are reported as means $\pm \mathrm{SE}$ for 5 animals. $\mathrm{Ct}=\mathrm{control}$; $\mathrm{dF} / \mathrm{dt}=\mathrm{time}$ derivatives of left ventricular force development. ${ }^{*} \mathrm{P}<0.05$ for lead $v s \mathrm{Ct}$ (one-way repeated measures ANOVA followed by the Tukey test).

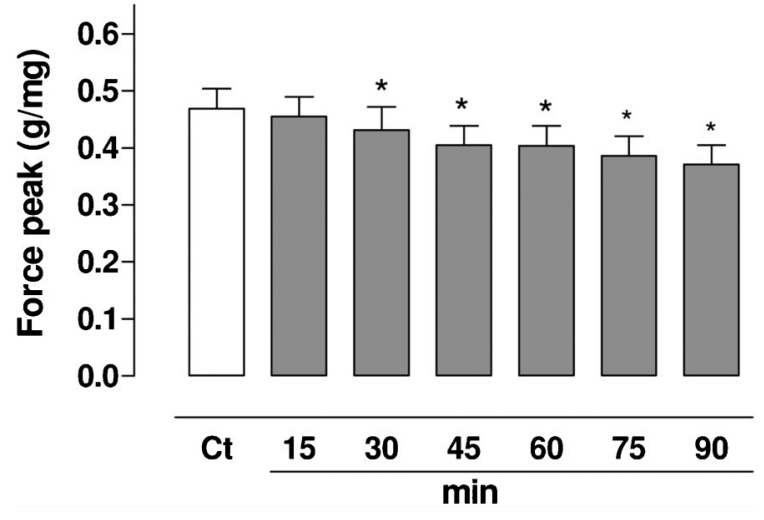

Figure 2. Effects of $8 \mu \mathrm{M}$ lead acetate on the time course of peak force of isometric force upon tetanic stimulation. Results are reported as means $\pm S E$ for 8 animals. $\mathrm{Ct}=$ control. ${ }^{*} \mathrm{P}<0.05$ for lead vs Ct (one-way repeated measures ANOVA followed by the Tukey test).
A
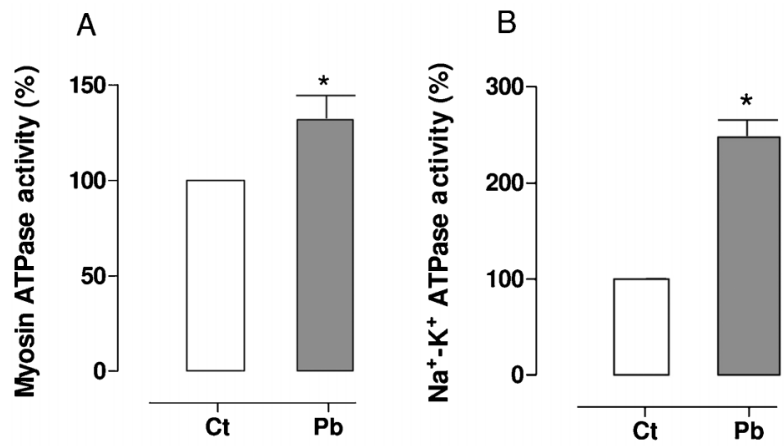

Figure 3. Myosin ATPase activity $(A)$ and $\mathrm{Na}^{+}, \mathrm{K}^{+}$-ATPase activity $(B)$ of control $(\mathrm{Ct})$ and lead $(\mathrm{Pb})$-exposed animals. Results are reported as means \pm SE for 6 animals. ${ }^{*} \mathrm{P}<0.05$ (Student $t$-test). 
reported, the increased $\mathrm{Na}^{+}, \mathrm{K}^{+}$-ATPase activity increases resting potential and induces positive inotropic effects and contractile synchronization (24). Therefore, we also measured $\mathrm{Na}^{+}, \mathrm{K}^{+}$-ATPase activity and found that it was increased (Figure 3).

\section{Discussion}

The results presented here demonstrate that acute administration of low concentrations of lead increases systolic left and right ventricular pressures and produces positive inotropic and lusitropic effects in cardiac muscle, both in vivo and in vitro. In addition, these results also suggested that lead is a calcium channel blocker. However, lead did not affect sarcoplasmic reticulum activity but did increase myosin ATPase and $\mathrm{Na}^{+}, \mathrm{K}^{+}-$ ATPase activity, which explains the positive inotropism and lusitropism. These findings suggest that the myocardial contractility changes that were induced by exposure to lead are independent of hypertension development.

Exposure to lead causes numerous damaging effects on human health $(1-4,25)$, which depend on blood concentration and exposure time (5). The hypertension induced by lead is associated with the inhibition of $\mathrm{Na}^{+}, \mathrm{K}^{+}$ATPases (26) and an accompanying reduction of the bioavailability of nitric oxide (27-29), increasing the release of endothelin $(30,31)$ and sympathetic activity and reducing parasympathetic tone (10-12), increasing oxidative stress (32-34), and increasing renin-angiotensin system activity (35).

Previous reports on rats exposed for 10 months to $60 \mathrm{ppm}$ lead acetate indicated increased myocardial inotropism and increased angiotensin-converting enzyme activity $(11,14)$. However, other reports have indicated that acute lead administration ( $30 \mu \mathrm{M}$ in the bath) to perfused rat hearts attenuates positive inotropic responses (15). In rat papillary muscles, acute $100 \mu \mathrm{M}$ lead in the bath, although not affecting sarcoplasmic reticulum activity, has a negative inotropic effect and reduces myosin ATPase activity (17). Lead action contributing to calcium channel blocking has also been reported in rat myocytes and Xenopus laevis oocytes (16). These findings, although contradictory, suggest that lead affects heart function. Moreover, it is necessary to emphasize that a positive inotropism was found with a lower lead concentration (14), while negative inotropism was found with a higher lead concentration (17).

Our results indicated that, after $60 \mathrm{~min}$, acute lead acetate administration increased systolic left and right ventricular pressures, and produced a positive inotropic effect in anesthetized rats while heart rate was unchanged. These results are similar to those reported by Carmignani et al. $(11,14)$ in an experimental model of chronic lead administration. Since these findings are based on acute exposure, they suggest that positive inotropic effects take place very early and are independent of hypertension development. Since acute lead administration increased both left and right ventricular systolic pressures and positive inotropic and lusitropic effects, these findings suggest increased sympathetic tone acting on the heart. Previous reports have already described the involvement of sympathetic nerve activity, along with reduction of baroreflex sensitivity and of parasympathetic tone in leadinduced hypertension (10-12).

However, another hypothesis that should be considered was that a low concentration of lead increases rat ventricular pressure by a direct effect, increasing myocardial contractility. To investigate this issue, the papillary muscle preparation was used to avoid external neural or humoral interferences that can be present in vivo. Our results indicated that the positive inotropic effect also occurred in the papillary muscles, suggesting a local myocardial action of lead, corroborating our in vivo results. To clarify the underlying mechanisms, we indirectly tested the activity of the sarcoplasmic reticulum using the PPP protocol (36). No changes in PPP were observed after lead administration, suggesting that the sarcoplasmic reticulum might not be involved. However, the reduced isometric tension, which was observed in the PRC, suggested that sarcolemmal calcium influx was reduced, in agreement with a previous report (16). This finding, although in contrast to the positive inotropic effect found, was reinforced by the fact that peak tetanic tension was reduced (Figure 2) since it is dependent on the sarcolemmal calcium influx or on the characteristics of contractile proteins. Thus, the decreased calcium influx could have reduced the peak tetanic tension.

However, the enhanced $\beta$-adrenergic response and the increased myosin $\mathrm{Ca}^{2+}$ ATPase activity (Figure 3A) may demonstrate the ability of acute lead administration to increase force and pressure in the isolated papillary muscle and ventricles. It is already known that sympathetic nerve terminals continue to release catecholamines in isolated preparations (37). The enhanced response to $\beta$-adrenoceptor stimulation may help maintain contractility both in vivo and in vitro and could explain why TPT tension was reduced (Figure 1). Moreover, $\beta$-adrenergic activation also regulates myosin ATPase activity through cyclic AMP. The cooperation of these two effects, the enhanced response to $\beta$-adrenoceptor stimulation and increased activity of myosin ATPase, may explain why the inotropic effects prevailed (Figure 1 and Table 1) (38). The last finding that could explain the positive inotropic effect is the increased $\mathrm{Na}^{+}, \mathrm{K}^{+}$-ATPase activity. It is a known fact that this activity produces intracellular sodium reduction, enhancing the $\mathrm{Na}^{+} / \mathrm{Ca}^{2+}$ exchanger activity, which reduces intracellular calcium and, consequently, force development. However, digitalis sensitivity is different regarding the alpha subunit of $\mathrm{Na}^{+}, \mathrm{K}^{+}$-ATPase. The alpha 1 subunit is distributed all over the plasma membrane and the alpha 2 and 3 subunits are expressed only in regions of superposition with the sarcoplasmic reticulum. This region has been defined as plasmerosome 
and $\mathrm{Na}^{+}, \mathrm{K}^{+}$-ATPase is usually co-expressed with the sodium/calcium exchanger. It is at this region that digitalis produces a positive inotropic effect because a low digitalis concentration inhibits $\mathrm{Na}^{+}, \mathrm{K}^{+}$-ATPase. However, to inhibit the alpha 1 isoform of $\mathrm{Na}^{+}, \mathrm{K}^{+}$-ATPase, digitalis concentration must attain toxic levels. A recent report has shown that the alpha 2 subunit is the isoform responsible for a positive inotropic effect (39). Then, the alpha 1 subunit of $\mathrm{Na}^{+}, \mathrm{K}^{+}$-ATPase has another function, mainly the regulation of ionic distribution and maintenance of resting potential. Adequate resting potential is necessary for the activation of an action potential. In the myocardium, small reductions of resting potential reduce the $\mathrm{Na}^{+}$fast inward current and then action potential conduction slows down. This reduces contraction because of reduced myocyte synchronization. It has been known for a long time that isolated preparations lose potassium permeability during experiments that also reduce resting potential. Increasing $\mathrm{Na}^{+}, \mathrm{K}^{+}$-ATPase activity increases the resting potential, promoting better synchronization of contraction and consequently peak force increases (24).

Our findings suggest that acute administration of lead acetate increases left and right ventricular pressures and myocardial contractility without affecting heart rate. In addition, the present results show, for the first time, that acute exposure to low lead concentrations produces positive inotropic and lusitropic effects independent of hypertension development. These effects seem to be the result of increased myosin ATPase and $\mathrm{Na}^{+}, \mathrm{K}^{+}$-ATPase

\section{References}

1. Pabello NG, Bolivar VJ. Young brains on lead: adult neurological consequences? Toxicol Sci 2005; 86: 211213, doi: 10.1093/toxsci/kfi221.

2. Patrick L. Lead toxicity part II: the role of free radical damage and the use of antioxidants in the pathology and treatment of lead toxicity. Altern Med Rev 2006; 11: 114127.

3. Prozialeck WC, Edwards JR, Nebert DW, Woods JM, Barchowsky A, Atchison WD. The vascular system as a target of metal toxicity. Toxicol Sci 2008; 102: 207-218, doi: 10.1093/toxsci $/ \mathrm{kfm} 263$

4. Roncal C, Mu W, Reungjui S, Kim KM, Henderson GN, Ouyang $X$, et al. Lead, at low levels, accelerates arteriolopathy and tubulointerstitial injury in chronic kidney disease. Am J Physiol Renal Physiol 2007; 293: F1391-F1396, doi: 10.1152/ajprenal.00216.2007.

5. Lustberg M, Silbergeld E. Blood lead levels and mortality. Arch Intern Med 2002; 162: 2443-2449, doi: 10.1001/ archinte.162.21.2443.

6. Navas-Acien A, Guallar E, Silbergeld EK, Rothenberg SJ. Lead exposure and cardiovascular disease - a systematic review. Environ Health Perspect 2007; 115: 472-482, doi: 10.1289/ehp.9785.

7. Hertz-Picciotto I, Croft J. Review of the relation between blood lead and blood pressure. Epidemiol Rev 1993; 15: 352-373. activities together with the enhanced $\beta$-adrenergic response. They suggest that myocardial contractility changes induced by lead might be independent of hypertension development. These results also suggest that short-term exposure to low lead concentrations might affect cardiovascular function and be potentially noteworthy in the context of epidemiological impact.

\section{Potential limitations of the study}

We used a fluid-filled manometric system to perform the hemodynamic experiments. By comparing the present results with those obtained using microtip pressure transducers, we observed that the present values obtained with a polyethylene catheter were lower than those obtained with the microtip catheter (40). Experiments using the microtip catheter are commonly performed in anesthetized rats, thereby reducing differences with the fluid-filled catheters. Because the use of anesthesia changes hemodynamic parameters, we used the fluid-filled manometric system to perform the present experiments, keeping in mind both the resonance effect of the catheter and dumping, which this manometric system produces. In any case, as the same fluid-filled manometric system was used to perform all experiments, we believe that the results presented here are acceptable.

\section{Acknowledgments}

Research supported by FAPES, CAPES and CNPq.

8. Schober SE, Mirel LB, Graubard BI, Brody DJ, Flegal KM. Blood lead levels and death from all causes, cardiovascular disease, and cancer: results from the NHANES III mortality study. Environ Health Perspect 2006; 114: 1538-1541.

9. Staessen JA, Bulpitt CJ, Fagard R, Lauwerys RR, Roels $H$, Thijs $L$, et al. Hypertension caused by low-level lead exposure: myth or fact? J Cardiovasc Risk 1994; 1: 87-97, doi: 10.1097/00043798-199406000-00014.

10. Boscolo P, Carmignani M. Neurohumoral blood pressure regulation in lead exposure. Environ Health Perspect 1988; 78: 101-106, doi: 10.1289/ehp.8878101.

11. Carmignani M, Volpe AR, Boscolo P, Qiao N, Di Gioacchino $M$, Grilli $A$, et al. Catcholamine and nitric oxide systems as targets of chronic lead exposure in inducing selective functional impairment. Life Sci 2000; 68: 401-415, doi: 10.1016/S0024-3205(00)00954-1.

12. Tsao DA, Yu HS, Cheng JT, Ho CK, Chang HR. The change of beta-adrenergic system in lead-induced hypertension. Toxicol Appl Pharmacol 2000; 164: 127-133, doi: 10.1006/ taap.1999.8871.

13. Hejtmancik MR Jr., Williams BJ. Effect of chronic lead exposure on the direct and indirect components of the cardiac response to norepinephrine. Toxicol Appl Pharmacol 1979; 51: 239-245, doi: 10.1016/0041008X(79)90466-6.

14. Carmignani M, Boscolo P, Poma A, Volpe AR. Kininergic 
system and arterial hypertension following chronic exposure to inorganic lead. Immunopharmacology 1999; 44: 105-110, doi: 10.1016/S0162-3109(99)00115-0.

15. Prentice RC, Kopp SJ. Cardiotoxicity of lead at various perfusate calcium concentrations: functional and metabolic responses of the perfused rat heart. Toxicol Appl Pharmacol 1985; 81: 491-501, doi: 10.1016/0041-008X(85)90420-X.

16. Bernal J, Lee JH, Cribbs LL, Perez-Reyes E. Full reversal of $\mathrm{Pb}^{++}$block of L-type $\mathrm{Ca}^{++}$channels requires treatment with heavy metal antidotes. J Pharmacol Exp Ther 1997; 282: 172-180.

17. Vassallo DV, Lebarch EC, Moreira CM, Wiggers GA, Stefanon I. Lead reduces tension development and the myosin ATPase activity of the rat right ventricular myocardium. Braz J Med Biol Res 2008; 41: 789-795, doi: 10.1590/ S0100-879X2008000900008.

18. Chan KM, Delfert $D$, Junger KD. A direct colorimetric assay for $\mathrm{Ca}^{2+}$-stimulated ATPase activity. Anal Biochem 1986; 157: 375-380, doi: 10.1016/0003-2697(86)90640-8.

19. Klotz C, Aumont MC, Berson G, Leger JJ, Preteseille M, Swynghedauw B. Cardiac myosin: preparation, ATPase in chronic heart hypertrophy. Recent Adv Stud Cardiac Struct Metab 1975; 5: 263-271.

20. Cappelli V, Bottinelli R, Poggesi C, Moggio R, Reggiani C. Shortening velocity and myosin and myofibrillar ATPase activity related to myosin isoenzyme composition during postnatal development in rat myocardium. Circ Res 1989; 65: 446-457, doi: 10.1161/01.RES.65.2.446.

21. Bradford MM. A rapid and sensitive method for the quantitation of microgram quantities of protein utilizing the principle of protein-dye binding. Anal Biochem 1976; 72: 248-254, doi: 10.1016/0003-2697(76)90527-3.

22. Stefanon I, Cade JR, Fernandes AA, Ribeiro Junior RF, Targueta GP, Mill JG, et al. Ventricular performance and $\mathrm{Na}^{+}-\mathrm{K}^{+}$ATPase activity are reduced early and late after myocardial infarction in rats. Braz J Med Biol Res 2009; 42: 902-911, doi: 10.1590/S0100-879X2009005000015.

23. Glitsch HG. Electrophysiology of the sodium-potassiumATPase in cardiac cells. Physiol Rev 2001; 81: 1791-1826.

24. Gelband H, Myerburg RJ, Hoffman BF, Bassett AL. Acetylcholine-induced reversal of canine and feline atrial myocardial depression during stretch, cardiac failure, and drug toxicity. Circ Res 1975; 37: 542-549, doi: 10.1161/ 01.RES.37.5.542.

25. Menke A, Muntner P, Batuman V, Silbergeld EK, Guallar E. Blood lead below $0.48 \mathrm{micromol} / \mathrm{L}$ (10 microg/dL) and mortality among US adults. Circulation 2006; 114: 13881394, doi: 10.1161/CIRCULATIONAHA.106.628321.

26. Weiler E, Khalil-Manesh F, Gonick HC. Effects of lead and a low-molecular-weight endogenous plasma inhibitor on the kinetics of sodium-potassium-activated adenosine triphosphatase and potassium-activated p-nitrophenylphosphatase. Clin Sci 1990; 79: 185-192.
27. Gonick HC, Ding Y, Bondy SC, Ni Z, Vaziri ND. Leadinduced hypertension: interplay of nitric oxide and reactive oxygen species. Hypertension 1997; 30: 1487-1492, doi: 10.1161/01.HYP.30.6.1487.

28. Navas-Acien A, Selvin E, Sharrett AR, Calderon-Aranda E, Silbergeld E, Guallar E. Lead, cadmium, smoking, and increased risk of peripheral arterial disease. Circulation 2004; 109: 3196-3201, doi: 10.1161/01.CIR.0000130848. 18636.B2.

29. Vaziri ND, Ding Y, Ni Z, Gonick HC. Altered nitric oxide metabolism and increased oxygen free radical activity in lead-induced hypertension: effect of lazaroid therapy. Kidney Int 1997; 52: 1042-1046, doi: 10.1038/ki.1997.426.

30. Grizzo LT, Cordellini S. Perinatal lead exposure affects nitric oxide and cyclooxygenase pathways in aorta of weaned rats. Toxicol Sci 2008; 103: 207-214, doi: 10.1093/toxsci/ kfn018.

31. Khalil-Manesh F, Gonick HC, Weiler EW, Prins B, Weber MA, Purdy RE. Lead-induced hypertension: possible role of endothelial factors. Am J Hypertens 1993; 6: 723-729.

32. Farmand F, Ehdaie A, Roberts CK, Sindhu RK. Leadinduced dysregulation of superoxide dismutases, catalase, glutathione peroxidase, and guanylate cyclase. Environ Res 2005; 98: 33-39, doi: 10.1016/j.envres.2004.05.016.

33. Ni Z, Hou S, Barton $\mathrm{CH}$, Vaziri ND. Lead exposure raises superoxide and hydrogen peroxide in human endothelial and vascular smooth muscle cells. Kidney Int 2004; 66: 2329-2336, doi: 10.1111/j.1523-1755.2004.66032.x.

34. Vaziri ND, Ding Y, Ni Z. Compensatory up-regulation of nitric-oxide synthase isoforms in lead-induced hypertension; reversal by a superoxide dismutase-mimetic drug. $J$ Pharmacol Exp Ther 2001; 298: 679-685.

35. Simoes MR, Ribeiro Junior RF, Vescovi MV, de Jesus HC, Padilha AS, Stefanon I, et al. Acute lead exposure increases arterial pressure: role of the renin-angiotensin system. PLoS One 2011; 6: e18730, doi: 10.1371/journal.pone.0018730.

36. Mill JG, Vassallo DV, Leite CM. Mechanisms underlying the genesis of post-rest contractions in cardiac muscle. Braz $J$ Med Biol Res 1992; 25: 399-408.

37. Endoh M, Hashimoto K. Pharmacological evidence of autonomic nerve activities in canine papillary muscle. Am J Physiol 1970; 218: 1459-1463.

38. Winegrad S, Weisberg A, Lin LE, McClellan G. Adrenergic regulation of myosin adenosine triphosphatase activity. Circ Res 1986; 58: 83-95, doi: 10.1161/01.RES.58.1.83.

39. Swift F, Tovsrud N, Enger UH, Sjaastad I, Sejersted OM. The $\mathrm{Na}^{+} / \mathrm{K}^{+}$-ATPase alpha2-isoform regulates cardiac contractility in rat cardiomyocytes. Cardiovasc Res 2007; 75: 109-117, doi: 10.1016/j.cardiores.2007.03.017.

40. Zimmer HG, Millar HD. Technology and application of ultraminiature catheter pressure transducers. Can J Cardiol 1998; 14: 1259-1266. 